\title{
Reaction from Isomeric Parent Ions in the Dissociation of Dimethylpyrroles
}

\author{
Tong Lin, Michael R. Asam, and Gary L. Glish \\ Department of Chemistry, University of North Carolina at Chapel Hill, Chapel Hill, North Carolina
}

\begin{abstract}
The major dissociation pathways of the $[\mathrm{M}-\mathrm{H}]^{+}$(loss of $\mathrm{NH}_{3}$ or $\mathrm{CH}_{4}$ ) and the $[\mathrm{M}+\mathrm{H}]^{+}$ (loss of $\mathrm{NH}_{3}$ or $\mathrm{CH}_{3}^{-}$) ions from dimethylpyrroles have been determined to occur from isomeric parent ions. For the $[\mathrm{M}-\mathrm{H}]^{+}$ion (formed by loss of a methyl hydrogen), loss of $\mathrm{NH}_{3}$ leads to the formation of the phenylium ion and is preceded by consecutive carbon ring expansions followed by a ring contraction to form protonated aniline. Loss of $\mathrm{CH}_{4}$ occurs after the first carbon ring expansion, which forms protonated picoline. The relative partitioning betwcen the two dissociation paths depends upon the internal energy content of the parent ion; the highest point on the potential energy surface is the second ring expansion step. The $[\mathrm{M}+\mathrm{H}]^{+}$ion reacts through a similar pathway via dihydro analogs of picoline and aniline. The proposed reaction pathways are supported by results of semiempirical molecular orbital calculations. (J Am Soc Mass Spectrom 1996, 7, 930-937)
\end{abstract}

G as-phase ion chemistry is a topic of wide interest. A critical question addressed by gas-phase ion chemistry is whether molecules retain their original structures upon ionization, or isomerize prior to fragmentation. Isomerization prior to fragmentation has been observed for many molecular ions, which implies that the barrier for isomerization is lower than that for fragmentation [1-3]. A lack of awareness or understanding of such isomerizations can make interpretation of mass spectra difficult or impossible. Tandem mass spectrometry $\mathrm{ms} / \mathrm{ms}$ is an important method that provides information on the structure and reaction of gas-phase ions because the parent-product ion relationship is clearly defined [4].

Collision-induced dissociation (CID) is the most common method to induce reactions in $\mathrm{ms} / \mathrm{ms}$ experiments. However, one of the reactions that can be effected by CID is isomerization [5, 6]. As an alternative to $\mathrm{CID}$, ion-molecule reactions can be used to probe ion structure [7]. Ion-molecule reactions have been used for solving a variety of ion structure problems and are especially useful in cases where CID causes isomerization. Ion-molecule reactions can distinguish isomers not only by their reactivity [8-19], but also by their rates of reactions $[10-13,16]$.

Often it is desirable to characterize the product ions that are formed from CID or ion-molecule reactions. To perform such experiments an instrument with the capability to perform multiple stages of mass spectrometry $\left(\mathrm{MS}^{n}\right)$ is needed. A quadrupole ion trap is

Address reprint requests to Dr. Gary L. Glish, Department of Chemistry, University of North Carolina at Chapel Hill, Chapel Hill, NC 27599-3290. one instrument capable of MS" experiments. Multiple stage $\mathrm{ms} / \mathrm{ms}$ experiments can be performed with high efficiency, separated in time, in a single analyzer, which facilitates the implementation of MS $^{n}$ experiments as opposed to beam instruments in which one analyzer is needed for each stage of $\mathrm{ms} / \mathrm{ms}$. Additionally, the quadrupole ion trap can readily effect both CID and ion-molecule reactions, in any combination, with not only reactivity, but also reaction rate constants accessible for the latter type of experiment [20-23].

In this article, the dissociations of ions generated from 2,5-dimethylpyrrole and its isomers are discussed. The initial impetus for this study came from the observation of a loss of $17 \mathrm{u}$ from the $[\mathrm{M}-\mathrm{H}]^{+}$ ion [24]. Although loss of $\mathrm{NH}_{3}$ likely should be an energetically favorable process versus a loss of $\mathrm{CH}_{5}$ (either as $\mathrm{CH}_{3}$, and $\mathrm{H}_{2}$ or $\mathrm{CH}_{4}$ and $\mathrm{H}^{\circ}$ ), from entropy considerations loss of $\mathrm{NH}_{3}$ from dimethylpyrroles appears to be an unlikely process. A priori, few people would predict this loss from $[\mathrm{M}-\mathrm{H}]^{+}$generated from dimethylpyrrole. These considerations are even more significant for the $\left[\mathrm{M}+\mathrm{H}^{+}\right.$ion because it undergoes a competitive loss of $\mathrm{CH}_{3}^{+}$. Although loss of $\mathrm{CH}_{3}^{-}$is unexpected because this dissociation involves an even electron ion going to an odd electron ion, it would not be unexpected to lose $\mathrm{H}_{2}$ subsequent to loss of $\mathrm{CH}_{3}$ to form an ion at $[\mathrm{MH}-17]^{+}$.

Via quadrupole ion trap $\mathrm{MS}^{n}$ experiments, which used both CID and ion-molecule reactions, along with isotopic labeling studies, we have determined that two structures exist for both the $[\mathrm{M}+\mathrm{H}]^{+}$and $[\mathrm{M}-\mathrm{H}]^{+}$ ions of 2.5-dimethylpyrrole. One structure dissociates by loss of ammonia and the other by loss of methane or methyl radical. These reactions have been investi- 
gated in detail to determine reaction pathways and product structures by using various capabilities of the quadrupole ion trap. These experiments provide evidence that the dissociations are not competitive from a single structure, but rather there is competitive formation of isomeric parent ions prior to dissociation. How common it is for isomeric species to coexist is unknown, but there is no a priori reason not to expect such occurrences. Certainly there have been many cases in which isomeric ions are formed from a given molecule, one of the most studied is toluene [25]. However, these isomers are typically distinguished by their differences in reactivity in ion-molecule reactions [26], not by collision-induced dissociation as is demonstrated in this work.

\section{Experimental}

\section{Materials}

Methane $(99.99 \%)$ and helium $(99.999 \%)$ were obtained from National Welders Supply Co., Inc. (Durham, NC). Deuterated methane (99.6\%) was obtained from Isotec Inc. (Miamisburg, $\mathrm{OH}$ ). Methane and deuterated methane were used as chemical ionization (CI) reagent gases, and helium was used as a bath gas. 2,5-Dimethylpyrrole, 2, 4-dimethylpyrrole, 2-ethylpyrrole, 2-picoline, 3-picoline, 4-picoline, and chlorobenzene were used as obtained from Aldrich (Milwaukee, WI) without further purification. 1,3,4$d_{3}$-2,5-Dimethylpyrrole was synthesized following a previously described method [27]. $N-d_{1}-2,5$-Dimethylpyrrole and 3,4- $d_{2}-2,5$-dimethylpyrrole were synthesized by vortexing 2,5-dimethylpyrrole with $\mathrm{D}_{2} \mathrm{O}$ and 1,3, 4- $d_{3}-2,5$-dimethylpyrrole with $\mathrm{H}_{2} \mathrm{O}$, respectively. The location of the deuterium at the expected sites in compounds was confirmed by ${ }^{1} \mathrm{H}$ NMR.

\section{Mass Spectrometry}

Experiments were performed with a modified Finnigan-MAT (San Jose, CA) quadrupole ion trap mass spectrometer with ITMS revision B software. The instrument was operated in the mass-selective instability mode with axial modulation $[28,29]$. Typical pressures were $2 \times 10^{-7}$ torr for the sample and $7 \times 10^{-4}$ torr for the He bath gas. For $\mathrm{CI}$ and ion-molecule reactions with methane, the methane pressure was $1.0 \times 10^{-5}$ torr.

Ions were generated first by either electron ionization or chemical ionization. After mass selection via mass-selective instability and resonance ejection [20, $21]$, the parent ion was allowed to undergo CID with $\mathrm{He}$ via resonant excitation. Resonant excitation involves the application of a rf voltage to the endcaps of the quadrupole ion trap at the resonant frequency of the parent ion. The amplitude of the resonant excitation rf (typical values of $300-400 \mathrm{mV}$, peak-to-peak) was low enough so that ions were not ejected from the quadrupole ion trap. Reagent gases for ion-molecule reactions either were leaked into the vacuum system through a Varian leak valve (model 9515106, Lexington, MA) to a typical pressure of $1 \times 10^{-5}$ torr or pulsed in through a pulse valve (General Valve Co. Iota One, Fairfield, NJ) with a pulse time of $300 \mu \mathrm{s}$.

Metastable ion measurements were performed with a Finnigan-MAT 900 mass spectrometer (Breman, Germany). Electron ionization (EI) or methane $\mathrm{CI}$ was used to ionize the sample, and kinetic-energy releases were determined by linked scanning at a constant $\mathrm{B}^{2} / \mathrm{E}$. This type of scan detects dissociations that occur in the first reaction region. All kinetic-energy releases were calculated on the basis of the peak half-height [30].

\section{Results}

Several approaches were used to investigate the fragmentation pathways and product ion structures of 2,5-dimethylpyrrole and its isomers. These include $\mathrm{ms} / \mathrm{ms}$ and $\mathrm{MS}^{n}$ of the naturally occurring ${ }^{13} \mathrm{C}$ ions, ion-molecule reactions, and deuterium labeling experiments. The results for each type of experiments are presented separately in subsequent text.

\section{Metastable Ions}

The observation of metastable ions is indicative of low energy dissociation pathways. Further insight into dissociations also may be inferred at times by measuring kinetic-energy releases associated with metastable dissociations [30]. Simple cleavage reactions typically are associated with small kinetic-energy releases, because there is little or no reverse activation energy and thus only the excess internal energy, which is statistically partitioned [31], contributes to the kinetic-energy release. Conversely, rearrangement reactions usually have a reverse activation energy associated with them so a fraction of this energy, which is assumed to depend upon the geometry of the transition state, is also partitioned into the kinetic-energy release [30].

For the $[\mathrm{M}-\mathrm{H}]^{+}$ion generated by EI of 2,5dimethylpyrrole, the loss of both 16 and $17 \mathrm{u}$ was observed in the metastable ion spectrum. The kineticenergy release for the loss of $16 \mathrm{u}$ is $104 \mathrm{meV}$; that for loss of $17 \mathrm{u}$ is $54 \mathrm{meV}$. The loss of both 15 and $17 \mathrm{u}$ was observed for the $[\mathrm{M}+\mathrm{H}]^{+}$ion. The kinetic-energy releases showed the same trend as those for the $[\mathrm{M}-\mathrm{H}]^{+}$ions, but were larger in magnitude. The loss of $15 \mathrm{u}$ had a kinetic-energy release value of $173 \mathrm{meV}$, whereas the loss of $17 \mathrm{u}$ had a kinetic-energy release of $95 \mathrm{meV}$. Residual CID may account, at least in part, for the increase in magnitude of the kinetic-energy release for the $[\mathrm{M}+\mathrm{H}]^{+}$because some of the $\mathrm{CI}$ reagent gas can leak into the reaction region.

These results provide little information on the reaction paths of the $[\mathrm{M}-\mathrm{H}]^{+}$and $[\mathrm{M}+\mathrm{H}]^{+}$parent ions. 
A large kinetic-energy release for loss of $17 \mathrm{u}$ would be indicative of a rearrangement and might suggest that this loss is $\mathrm{NH}_{3}$. The small kinetic-energy release measured is consistent with a simple cleavage or a rearrangement to an ion that can lose $\mathrm{NH}_{3}$ from a loose complex that is at the highest energy along the reaction path. The one thing that can be determined from the kinetic-energy release data is that the loss of $17 u$ is not via consecutive reactions where the second reaction is loss of $\mathrm{H}^{*}$ or $\mathrm{H}_{2}$ because loss of 15 or $16 \mathrm{u}$ from the appropriate parent ion has a greater kinetic-energy release than loss of $17 \mathrm{u}$. However, the possibility of loss of $\mathrm{H}^{-}$or $\mathrm{H}_{2}$ followed by loss of 15 or 16 , respectively, is not excluded.

\section{${ }^{13} \mathrm{C}$ Experiments}

Experiments were reproduced for 2,5-dimethylpyrrole according to a previous report [24]. Results confirmed that under CID conditions, [M $-\mathrm{H}]^{+}$of 2,5-dimethylpyrrole dissociates to product ions at $m / z 77$ and 78 via loss of $\mathrm{NH}_{3}$ and $\mathrm{CH}_{4}$, respectively. The $\mathrm{MS}^{3}$ reaction sequences are shown in eqs 1 and 2.

$$
\begin{gathered}
\underset{95}{\mathrm{M}^{+\cdot}} \stackrel{\mathrm{MS}^{2}}{\longrightarrow}[\mathrm{M}-\mathrm{H}]^{+} \stackrel{\mathrm{MS}^{3}}{\longrightarrow} \mathrm{C}_{6} \mathrm{H}_{5}^{+}+\mathrm{NH}_{3} \\
\underset{95}{\mathrm{M}^{+}} \stackrel{\mathrm{MS}^{2}}{\longrightarrow}[\mathrm{M}-\underset{94}{\mathrm{H}}]^{+} \stackrel{\mathrm{MS}^{3}}{\longrightarrow} \underset{78}{\mathrm{C}_{5} \mathrm{H}_{4} \mathrm{~N}^{+}}+\mathrm{CH}_{4}
\end{gathered}
$$

In the CID $\mathrm{ms} / \mathrm{ms}$ of protonated 2,5-dimethylpyrrole, product ions at $m / z 79$ and 81 were observed from loss of 17 and $15 \mathrm{u}$ respectively. The possible elemental compositions of the neutral lost are shown in eqs 3 and 4.

$$
\begin{aligned}
& {\left[\mathrm{M}+\mathrm{H}_{96}^{+} \stackrel{-17}{\longrightarrow} \mathrm{C}_{6} \mathrm{H}_{79}^{+}+\mathrm{N}+3 \mathrm{H}\right. \text { or }} \\
& \times \mathrm{C}_{5} \mathrm{H}_{5} \mathrm{~N}^{+}+\mathrm{C}+5 \mathrm{H} \\
& {[\mathrm{M}+\underset{96}{+\mathrm{H}}]^{+} \stackrel{-15}{\longrightarrow} \mathrm{C}_{5} \mathrm{H}_{71} \mathrm{~N}^{+}+\mathrm{C}+3 \mathrm{H} \text { or }} \\
& \times \underset{81}{\mathrm{C}_{6} \mathrm{H}_{9}^{+}}+\mathrm{N}+\mathrm{H}
\end{aligned}
$$

To determine the product-ion formulae, the CID tandem mass spectra of all the ${ }^{12} \mathrm{C}$-containing parent ion and naturally occurring ${ }^{13} \mathrm{C}$-containing parent ion were compared. Because the product ions differ in mass by $2 \mathrm{u}$, this case is easier to interpret than the molecular ion reaction path shown in eqs 1 and 2 . There are six carbons in the parent ion, so for a parent ion that contains one ${ }^{13} \mathrm{C}$, if the loss of a neutral fragment that contains one carbon is assumed, the probability that the neutral contains the ${ }^{13} \mathrm{C}$ atom is 1:5. Thus, for the loss of $17 \mathrm{u}$, if there is a carbon involved in the neutral loss, a 1:5 ratio of $\mathrm{m} / \mathrm{z}$ 79:80 should be observed in the CID spectrum of the ${ }^{13} \mathrm{C}$ parent ion; $m / z 79$ results from loss of $\left[{ }^{13} \mathrm{C}+5 \mathrm{H}\right]$ and $m / z 80$ from loss of $\left[{ }^{12} \mathrm{C}+5 \mathrm{H}\right]$. If no carbon, but a nitrogen is involved in the neutral loss, $m / z 79$ in the CID spectrum of the all ${ }^{12} \mathrm{C}$ isotopomer should shift completely to $m / z 80$ in the CID spectrum of the ${ }^{13} \mathrm{C}$-containing parent ion. The same analysis can be applied to the loss of $15 \mathrm{u}$, in which a 1:5 ratio of $\mathrm{m} / \mathrm{z}$ 81:82 observed in the CID spectrum of the ${ }^{13} \mathrm{C}$-containing parent ion indicates that a carbon is involved in the neutral loss; otherwise, a nitrogen is indicated. To make the optimum comparison, the absolute abundance for both ${ }^{12} \mathrm{C}$ and ${ }^{13} \mathrm{C}$ parent ions should be similar. Thus, a longer ionization time was used to form the ${ }^{13} \mathrm{C}$ species. With similar parent ion abundances, the parameters for collision-induced dissociation were the same for the two experiments. The results are shown in Table 1 . The peak that corresponds to loss of $17 \mathrm{u}$ shifts quantitatively $1 \mathrm{u}$ higher and the $m / z 81$ ion in the CID spectrum of ${ }^{12} \mathrm{C}$ parent ion is divided between $m / z \quad 81$ and 82 in the CID spectrum of the ${ }^{13} \mathrm{C}$-containing parent ion in an abundance ratio of 1:5. Thus, the loss of $17 \mathrm{u}$ is due to the loss of $\mathrm{NH}_{3}$ and the loss of $15 \mathrm{u}$ is due to the loss of $\mathrm{CH}_{3}^{*}$.

Two isomers of 2,5-dimethylpyrrole-2,4-dimethylpyrrole and 2-ethylpyrrole-also were investigated for similarities in fragmentation pathways. Nearly identical results as those obtained for 2,5-dimethylpyrrole were found for both $[\mathrm{M}-\mathrm{H}]^{+}$and $[\mathrm{M}+\mathrm{H}]^{+}$ ions from 2,4-dimethylpyrrole. However, for 2-ethylpyrrole, completely different fragmentation pathways were observed as shown in eqs 5 and 6 . Comparison of the $\mathrm{ms} / \mathrm{ms}$ of ${ }^{12} \mathrm{C}$ parent ion with the ${ }^{13} \mathrm{C}$ parent ion confirmed the indicated fragmentation pathways shown in eqs 5 and 6.

$$
\begin{aligned}
& \mathrm{M}^{+\cdot}: \quad \mathrm{C}_{6} \mathrm{H}_{9} \mathrm{~N}^{+\cdot} \stackrel{-15}{\longrightarrow} \mathrm{C}_{5} \mathrm{H}_{6} \mathrm{~N}^{+}+\mathrm{CH}_{3} \\
& \mathrm{MH}^{+}: \quad \mathrm{C}_{6} \mathrm{H}_{96} \mathrm{~N}^{+} \stackrel{-28}{\longrightarrow} \underset{68}{\mathrm{C}_{4} \mathrm{H}_{6} \mathrm{~N}^{+}}+\mathrm{C}_{2} \mathrm{H}_{4}
\end{aligned}
$$

Protonation of picoline (2-,3-, and 4-) generates an ion with the same elemental composition as $[\mathrm{M}-\mathrm{H}]^{+}$ from dimethylpyrrole. $\mathrm{ms} / \mathrm{ms}$ of the protonated picolines produced the same product ions as those observed for $[\mathrm{M}-\mathrm{H}]^{+}$of the dimethylpyrroles. Comparison of the CID spectra of the ${ }^{12} \mathrm{C}$ and ${ }^{13} \mathrm{C}$ parent ions confirmed that the neutral losses from the protonated picolines are of $\mathrm{NH}_{3}$ and $\mathrm{CH}_{4}$.

Table 1. Percent of total intensity $\mathrm{MS}^{3}$ experiments for ${ }^{12} \mathrm{C}$ and ${ }^{13} \mathrm{C}$ protonated 2,5-dimethylpyrrole

\begin{tabular}{lcc}
\hline$m / z$ & ${ }^{12} \mathrm{C}$ Spectrum & ${ }^{13} \mathrm{C}$ Spectrum \\
\hline \hline 79 & 60.3 & 50.2 \\
80 & & 42.0 \\
81 & 39.7 & 7.8 \\
82 & & 7 \\
\hline
\end{tabular}




\section{Ion-Molecule Reactions}

The first generation product ion $(m / z$ 79) formed by loss of $\mathrm{NH}_{3}$ from $[\mathrm{M}+\mathrm{H}]^{+}$exclusively lost $\mathrm{H}_{2}$ in the MS $^{3}$ experiment. The product ion at $m / z 77$ from both EI $\mathrm{MS}^{3}$ (eq 1) and CI MS ${ }^{3}$ of 2,5-dimethylpyrrole was found to react with methane to give $m / z$ 91. Phenylium ion $\mathrm{C}_{6} \mathrm{H}_{5}^{+}(\mathrm{m} / z$ 77) has been shown to undergo a reaction with methane to give $\mathrm{C}_{7} \mathrm{H}_{7}^{+}(m / z$ 91) $[10,11]$, and the rate constant for this reaction has been determined to be $0.6 \times 10^{-10} \mathrm{~cm}^{3}$ molecule $\mathrm{s}^{-1} \mathrm{~s}^{-1}$ by ion cyclotron resonance (ICR) [10].

As a reference experiment, $\mathrm{C}_{6} \mathrm{H}_{5}^{+}$was generated from chlorobenzene and allowed to react with methane (eqs 7 and 8). It previously was noted that under EI conditions chlorobenzene can give a fraction of $\mathrm{C}_{6} \mathrm{H}_{5}^{+}$ ions (presumably acyclic) that react with a rate constant several orders of magnitude lower than phenylium ions [12]. However, by generating $\mathrm{C}_{6} \mathrm{H}_{5}^{+}$ via CID in the quadrupole ion trap, formation of the acyclic isomer can be avoided [32].

$$
\begin{array}{ll}
\mathrm{MS}^{2}: & \mathrm{C}_{6} \mathrm{H}_{5} \mathrm{Cl}^{+\cdot} \underset{\mathrm{He}}{\stackrel{\mathrm{ClD}}{\longrightarrow}} \mathrm{C}_{6} \mathrm{H}_{5}^{+}+\mathrm{Cl}^{\cdot} \\
\mathrm{MS}^{3}: & \mathrm{C}_{6} \mathrm{H}_{5}^{+} \underset{77}{\stackrel{\mathrm{I} / \mathrm{M}}{\underset{\mathrm{CH}_{4}}{\longrightarrow}}} \mathrm{C}_{7} \mathrm{H}_{7}^{+}+\mathrm{H}_{2}
\end{array}
$$

The rate constant for this ion-molecule reaction can be used as a benchmark to compare the rate constants obtained for $\mathrm{C}_{6} \mathrm{H}_{5}^{+}$ions generated from dimethylpyrroles and other isomers (Table 2). Within experimental error (mairly the accuracy of the pressure of $\mathrm{CH}_{4}$ ), the rate constants indicate that all the $\mathrm{C}_{6} \mathrm{H}_{5}^{+}$ ions are phenylium. The difference between the rate constants determined in this work and the previously published value is likely to be due to collisional stabilization of some of the excited adducts in the quadrupole ion trap as a result of the helium buffer gas.

To support further the assignment of $\mathrm{C}_{6} \mathrm{H}_{5}^{+}$as phenylium ion, the structure of the $\mathrm{C}_{7} \mathrm{H}_{7}^{+}$product ion was determined. There are at least three possible isomers for $\mathrm{C}_{7} \mathrm{H}_{7}^{+}$(tropylium, benzyl, and tolyl), whose unique reactivities with neutral molecules make them distinguishable [5, 13-18]. Benzyl ions react with $x y-$ lene, tolyl ions react with methane, and tropylium is unreactive with both $[5,13,14,17]$. Therefore, the

Table 2. Rate constants for the $\mathrm{C}_{6} \mathrm{H}_{5}^{+}$reaction with methane $\left(\times 10^{10} \mathrm{~cm}^{3}\right.$ molecule $\left.{ }^{-1} \mathrm{~s}^{-1}\right)$

\begin{tabular}{lll}
\hline & \multicolumn{2}{c}{ lonization method } \\
\cline { 2 - 3 } Sample & $\mathrm{El}$ & $\mathrm{Cl}$ \\
\hline \hline Chlorobenzene & 2.3 & \\
2, 5-Dimethylpyrrole & 2.9 & 2.0 \\
2, 4-Dimethylpyrrole & 2.0 & 2.0 \\
2-Picoline & & 1.8 \\
3-Picoline & & 3.2 \\
4-Picoline & & 1.7 \\
\hline
\end{tabular}

reactivity of $\mathrm{C}_{7} \mathrm{H}_{7}^{+}$can be used to differentiate the isomers as shown in eqs 9,10 , and 11 .

$$
\begin{aligned}
& \mathrm{C}_{7} \mathrm{H}_{7}^{+}+\text {xylene } \rightarrow \mathrm{C}_{9} \mathrm{H}_{11}^{+} \quad \text { benzyl } \\
& \mathrm{m} / \mathrm{z} 119 \\
& \mathrm{C}_{7} \mathrm{H}_{7}^{+}+\mathrm{CH}_{4} \rightarrow \mathrm{C}_{8} \mathrm{H}_{9}^{+} \quad \text { tolyl } \\
& \mathrm{C}_{7} \mathrm{H}_{7}^{+} \rightarrow \text { no reaction tropylium }
\end{aligned}
$$

Although it has been reported that the $\mathrm{C}_{7} \mathrm{H}_{7}^{+}$ion formed in ICR experiments has the tropylium structure [12], experiments with the quadrupole ion trap show that only the benzyl ion is formed under these experimental conditions [33]. For the $\mathrm{C}_{7} \mathrm{H}_{7}^{+}(m / z$ 91) from dimethylpyrrole reaction sequences, no reaction was observed with methane. These $\mathrm{m} / \mathrm{z} 91$ ions were observed to react completely with xylene to give $m / z$ 119 , as did $m / z 91$ ions formed from the reaction of methane with phenylium formed from chlorobenzene. These observations further support the assignment of the product ion $\mathrm{C}_{6} \mathrm{H}_{5}^{+}$as phenylium ion.

The overall reaction pathways for both 2,4 - and 2,5-dimethylpyrrole are as given in eqs 12 and 13 . Electron ionization:

$$
95\left(\mathrm{M}^{+}\right) \underset{-\mathrm{H}}{\stackrel{\mathrm{CID}}{\longrightarrow}} 94 \underset{-\mathrm{NH}_{3}}{\stackrel{\mathrm{CID}}{\longrightarrow}} 77 \underset{\mathrm{CH}_{4}}{\stackrel{\mathrm{I} / \mathrm{M}}{\longrightarrow}} 91 \underset{\text { xylene }}{\stackrel{\mathrm{I} / \mathrm{M}}{\longrightarrow}} 119
$$

Chemical ionization

$$
96\left(\mathrm{MH}^{+}\right) \underset{-\mathrm{NH}_{3}}{\stackrel{\mathrm{CID}}{\longrightarrow}} 79 \underset{-\mathrm{H}_{2}}{\stackrel{\mathrm{CID}}{\longrightarrow}} 77 \underset{\mathrm{CH}_{4}}{\stackrel{\mathrm{I} / \mathrm{M}}{\longrightarrow}} 91 \underset{\text { xylene }}{\stackrel{\mathrm{I} / \mathrm{M}}{\longrightarrow}} 119
$$

\section{Deuterium Labeling}

Because the loss of $\mathrm{NH}_{3}$ obviously involves a rather complex rearrangement, several experiments with deuterated variants of 2,5-dimethylpyrrole were performed to determine the source of the hydrogens involved in the $\mathrm{NH}_{3}$ loss. The first experiment used $\mathrm{CD}_{4}$ as the $\mathrm{CI}$ reagent gas instead of $\mathrm{CH}_{4} \cdot \mathrm{ms} / \mathrm{ms}$ of $[\mathrm{M}+$ $D]^{+}$gave a 1:2.4 ratio for the loss of $\mathrm{NH}_{2} \mathrm{D}: \mathrm{NH}_{3}$, which indicates, within experimental error, that the deuterium is randomized completely. For the loss of $\mathrm{CH}_{2} \mathrm{D}: \mathrm{CH}_{3}$, however, the observed ratio was 1:2.7, which indicates incomplete randomization of the deuterium.

To resolve the contradiction in the degree of randomization of the deuterium, specifically deuterated compounds were examined. $\mathrm{ms} / \mathrm{ms}$ of the molecular ion of $N-d_{1}-2,5$-dimethylpyrrole $(\mathrm{m} / z 96)$ yielded only product ions at $m / z 95$, with none at $m / z$ 94. This shows that the nitrogen hydrogen is not involved in the initial hydrogen loss from the molecular ion. Dissociation of the $[\mathrm{M}-\mathrm{H}]^{+}$ion produced $m / z 77,78$, and 
Table 3. $\mathrm{MS}^{3}$ data of $N-d_{1}-2,5$-dimethylpyrrole

\begin{tabular}{llll}
\hline $\mathrm{M}-\mathrm{H}]^{+}$ & & & \\
$m / z 95 \rightarrow$ & $m / 277$ & $m / 278$ & $m / 279$ \\
\hline \multirow{3}{*}{ Ratio } & $-\mathrm{NH}_{2} \mathrm{D}$ & $-\mathrm{NH}_{3}$ & \\
\hline \hline Theoretical $^{\mathrm{a}}$ & & $-\mathrm{CH}_{3} \mathrm{D}$ & $-\mathrm{CH}_{4}$ \\
& 3.0 & 5.0 & \\
Experimental & 3.0 & 1.0 & 1.0 \\
& & 5.0 & \\
& & 1.0 & 4.6 \\
\hline
\end{tabular}

${ }^{a}$ Calculated by assuming complete randomization of $H$ and $D$.

79 as product ions. Table 3 shows the different dissociation pathways that can contribute to the different product ions.

The product ion at $m / z 78$ can be formed by two dissociation pathways: one from the loss of $\mathrm{NH}_{3}$; the other from the loss of $\mathrm{CH}_{3} \mathrm{D}$. The contributions of the two species were deconvoluted by reacting the ion formed from loss of $\mathrm{NH}_{3}$ (phenylium) with methane. The remaining (unreactive) ion abundance then was attributed to the ion formed from loss of $\mathrm{CH}_{3} \mathrm{D}$. Protonated $N-d_{1}-2,5$-dimethylpyrrole $(m / z$ 97) also was examined (see Table 4). In this case, there is no problem with formation of isobaric product ions. The ratios of 3.0:5.0 and 1.0:2.1 for loss of $\mathrm{NH}_{2} \mathrm{D}: \mathrm{NH}_{3}$ from $N-d_{1-}$ 2,5-dimethylpyrrole for $\mathrm{EI}$ and $\mathrm{CI}$ experiments, respectively, were found to be very close to theoretical ratios for complete randomization of the deuterium, whereas for the loss of $\mathrm{CH}_{4}$ and $\mathrm{CH}_{3}$, the data indicate incomplete randomization.

The same experiments were performed for $3,4-d_{2}$ 2,5-dimethylpyrrole $\left(\mathrm{M}^{+\cdot}\right.$ of $\left.\mathrm{m} / \mathrm{z}=97\right)$. Loss of $\mathrm{H}$ is again the major dissociation channel for the molecular ion, but a small amount of $\mathrm{m} / \mathrm{z} 95$ was observed from

Table 4. $\mathrm{MS}^{2}$ data of protonated $N-d_{1}-2,5$-dimethylpyrrole

\begin{tabular}{lcc}
\hline$[\mathrm{M}+\mathrm{H}]^{+}$ & & \\
$m / z 97 \rightarrow$ & $m / z 79: m / z 80$ & $m / z 81: m / z 82$ \\
\hline Ratio $^{2}$ & $-\mathrm{NH}_{2} \mathrm{D}:-\mathrm{NH}_{3}$ & $-\mathrm{CH}_{2} \mathrm{D}:-\mathrm{CH}_{3}$ \\
\hline \hline Theoretical $^{\circ}$ & $1.0: 2.3$ & $1.0: 2.3$ \\
Experimental $^{2}$ & $1.0: 2.1$ & $1.0: 3.1$
\end{tabular}

${ }^{a}$ Calculated by assuming complete randomization of $H$ and $D$. loss of $\mathrm{D}$. The results for $\mathrm{MS}^{3}$ of the molecular ion and $\mathrm{MS}^{2}$ of the protonated molecule are shown in Tables 5 and 6, respectively. Product ions at $\mathrm{m} / \mathrm{z} 78$ and 79 from dissociation of the molecular ion and another at $\mathrm{m} / \mathrm{z} 81$ from dissociation of the protonated species can be formed from either the loss of $\mathrm{NH}_{3}$ isotopomers or the loss of $\mathrm{CH}_{4}$ isotopomers. Again the ion-molecule reaction with methane (eq 13) was used to deconvolute the isobaric reaction products. The ratios of 1.0:4.4:3.3 and 1.0:5.8:6.4 for the loss of $\mathrm{NHD}_{2}: \mathrm{NH}_{2} \mathrm{D}: \mathrm{NH}_{3}$ are in close agreement with the theoretical ratios for complete randomization of the deuterium. Again, only partial H/D scrambling is observed for the loss of $\mathrm{CH}_{4}$ and $\mathrm{CH}_{3}$ isotopomers.

\section{Effect of the Ion Formation Method}

The $m / z 94$ ion $[\mathrm{M}-\mathrm{H}]^{+}$can be formed either by EI fragmentation of 2,5-dimethylpyrrole $(\mathrm{m} / \mathrm{z}$ 95) or by CID of the $m / z 95$ ion that has been mass selected previously. We noted earlier that $\mathrm{ms} / \mathrm{ms}$ in the quadrupole ion trap did not cause isomerization, whereas electron ionization did in the formation of phenylium from chlorobezene. Thus, the $\mathrm{m} / \mathrm{z} 94$ ion formed by EI fragmentation is expected to have more internal energy than the ion formed by CID. CID spectra of $m / z 94$ formed by the two different routes were obtained to investigate the effect of internal energy. A ratio of 1:3 was obtained for the $\mathrm{m} / \mathrm{z}$ 77:78 product ions from $m / z 94$ formed by EI fragmentation, and a ratio of $1: 7$ was obtained from $\mathrm{m} / \mathrm{z} 94$ formed by CID.

Table 5. $\mathrm{MS}^{3}$ of 3,4-d $d_{2}-2,5$-dimethylpyrrole

\begin{tabular}{lllll}
\hline $\mathrm{M}-\mathrm{H}]^{+}$ & & & & \\
$m / z 96 \rightarrow$ & $m / z 77$ & $m / z 78$ & $m / z 79$ & $m / z 80$ \\
\hline \multirow{4}{*}{ Ratio } & $-\mathrm{NHD}_{2}$ & $\begin{array}{l}-\mathrm{NH}_{2} \mathrm{D} \\
-\mathrm{CH}_{2} \mathrm{D}_{2}\end{array}$ & $\begin{array}{l}-\mathrm{NH}_{3} \\
-\mathrm{CH}_{3} \mathrm{D}\end{array}$ & $-\mathrm{CH}_{4}$ \\
\hline \hline Theoretical $^{\mathrm{a}}$ & 1.0 & 5.0 & 3.3 & \\
& & 1.0 & 2.6 & 1.0 \\
Experimental $^{2}$ & 1.0 & 4.4 & 3.3 & \\
& & - & 0.6 & 1.0 \\
\hline
\end{tabular}

${ }^{a}$ Calculated by assuming complete randomization of $H$ and $D$.

Table 6. $\mathrm{MS}^{2}$ of protonated 3,4-d $d_{2}-2,5$-dimethylpyrrole

\begin{tabular}{|c|c|c|c|c|c|}
\hline \multicolumn{6}{|l|}{$\overline{[M+H]^{+}}$} \\
\hline$m / z 98 \rightarrow$ & $m / 279$ & $m / z 80$ & $m / z 81$ & $m / z 82$ & $m / z 83$ \\
\hline Ratio & $-\mathrm{NHD}_{2}$ & $-\mathrm{NH}_{3} \mathrm{D}$ & $\begin{array}{l}-\mathrm{NH}_{3} \\
-\mathrm{CHD}_{2} \\
\end{array}$ & $-\mathrm{CH}_{2} \mathrm{D}$ & $-\mathrm{CH}_{3}$ \\
\hline \multirow[t]{2}{*}{ Theoretical $^{\mathrm{a}}$} & 1.0 & 7.0 & 7.0 & & \\
\hline & & & 1.0 & 7.0 & 7.0 \\
\hline \multirow[t]{2}{*}{ Experimental } & 1.0 & 5.8 & 6.4 & & \\
\hline & & & - & 1.0 & 3.3 \\
\hline
\end{tabular}

${ }^{a}$ Calculated by assuming complete randomization of $H$ and $D$. 


\section{Discussion}

The dissociation of the $[\mathrm{M}-\mathrm{H}]^{+}$ion $\mathrm{C}_{6} \mathrm{H}_{8} \mathrm{~N}^{+}$will be discussed first because ions of the same formula could be generated from other compounds (e.g., picolines). The $[\mathrm{M}-\mathrm{H}]^{+}$ion from both 2,4- and 2,5-dimethylpyrrole and the isomeric $[\mathrm{M}+\mathrm{H}]^{+}$ions from all the picolines (2-, 3-, and 4-) undergo the same reactionsloss of $\mathrm{CH}_{4}$ and $\mathrm{NH}_{3}$. The product ion in all cases for the loss of $\mathrm{NH}_{3}$ is phenylium. These results suggest that the ions generated from the dimethylpyrroles and protonated picoline (methylpyridine) rearrange to a common structure. This rearrangement is due, in part, to the energy imparted during ionization, but isomerization during collisional activation cannot be precluded as a partial contributor to the isomerized ion population.

The deuterium labeling experiments indicate that the $[\mathrm{M}-\mathrm{H}]^{+}$ion is formed by loss of a methyl hydrogen from the molecular ion of dimethylpyrrole, which initially gives structure 1 .

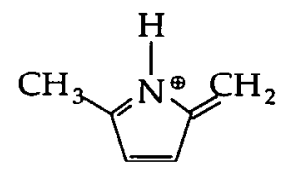

1

Semiempirical calculations (MOPAC version 6.0, AM1 Hamiltonians calculation) [34] indicate that the heat of formation of 1 is approximately $36 \mathrm{kcal} / \mathrm{mol}$ greater than the heat of formation of protonated picoline. Thus, the rearrangement (ring expansion) to the picoline may be rather facile. This provides a common reacting structure for the different $\mathrm{C}_{6} \mathrm{H}_{8} \mathrm{~N}^{+}$ions with the exception of the position of the methyl group on the pyridine ring. Because the different positional isomers all react nearly identically, either the methyl group can move around the ring or its position is unimportant in the dissociation (for 2,4-dimethylpyrrole semiempirical calculations indicate a slightly more stable ion formed by loss of a hydrogen from the 2-methyl group versus loss from the 4-methyl group).

Although the data certainly suggest that the ions generated from dimethylpyrrole rearrange to the protonated picoline structure, the deuterium labeling experiments indicate this is not the reacting structure for at least one of the dissociation pathways. In all cases, there is a significant difference in the amount of deu- terium scrambling in the ions that dissociate via $\mathrm{CH}_{4}$ loss versus those that dissociate by $\mathrm{NH}_{3}$ loss. For the loss of $\mathrm{NH}_{3}$, all the experiments indicate almost complete $\mathrm{H} / \mathrm{D}$ scrambling, whereas less scrambling is observed for the $\mathrm{CH}_{4}$ loss. These results can be rationalized based on different reacting structures.

Table 7 shows different isomeric structures for $[\mathrm{M}-\mathrm{H}]^{+}$of $\mathrm{C}_{6} \mathrm{H}_{9} \mathrm{~N}$ and their calculated heats of formation. From the protonated picoline 2, a ring expansion can occur to generate structure 3. Such a ring expansion would be similar to that proposed for toluene [25]. Structure 3 has a similar heat of formation as that for structure 1; thus some fraction of the ion population could have enough energy to undergo this reaction, and in addition energy also is being input into the system by collisional activation. Structure 3 should be able to rearrange to either structure 2 or 4 , both of which have similar stabilities. Structure 3 is expected to be a favorable structure for H/D scrambling. In addition, protonated aniline has been shown to undergo statistical $\mathrm{H} / \mathrm{D}$ scrambling on the time scale of the quadrupole ion trap if there is sufficient internal energy [32]. It has also been shown that the predominate dissociation of protonated aniline in the quadrupole ion trap is loss of $\mathrm{NH}_{3}[32,35]$.

The transition state in the rearrangement from 2 to 3 is expected to be the highest point on the reaction surface, at least in this region of the pathway, and thus more than $36 \mathrm{kcal} / \mathrm{mol}$ should be required to effect the rearrangement. The greater than $36-\mathrm{kcal} / \mathrm{mol}$ barrier for the rearrangement of structure 2 to 3 limits the fraction of ions than can rearrange to the structure that loses $\mathrm{NH}_{3}$. However, as the internal energy of the system is increased, more ions should be able to lose $\mathrm{NH}_{3}$, as is observed when the $[\mathrm{M}-\mathrm{H}]^{+}$ion is formed by direct fragmentation following electron ionization. This population of ions is expected to have more internal energy because there is a greater kinetic shift associated with fragmentation following ionization. With increased internal energy, a greater fraction of the ions are able to rearrange to protonated aniline and subsequently lose $\mathrm{NH}_{3}$ (the observed ratio of [loss of $\mathrm{NH}_{3}$ ]/[loss of $\mathrm{CH}_{4}$ ] increases by about a factor of 2).

For the protonated dimethylpyrroles potential reference compounds were not available commercially. However, semiempirical calculations were performed for a series of structures analogous to $[\mathrm{M}-\mathrm{H}]^{+}$, and their calculated heats of formation are shown in Table 8. Pyrrole is a carbon base [36] as shown in structure 5

Table 7. Different isomeric structures for $[\mathrm{M}-\mathrm{H}]^{+}$of $\mathrm{C}_{6} \mathrm{H}_{9} \mathrm{~N}$ and their calculated heats of formation $(\mathrm{kcal} / \mathrm{mol})$

$\Delta H_{i}=c_{210}^{1}$


Table 8. Different isomeric structures for $[\mathrm{M}+\mathrm{H}]^{+}$of $\mathrm{C}_{6} \mathrm{H}_{9} \mathrm{~N}$ and their calculated heats of formation $(\mathrm{kcal} / \mathrm{mol})$

(1)

in Table 8. All the structures have very similar heats of formation. Thus, it would be expected that much less energy would be required to observe loss of $\mathrm{NH}_{3}$ relative to loss of $\mathrm{CH}_{3}$. This expectation is supported by the greatly increased loss of $\mathrm{NH}_{3}$ versus $\mathrm{CH}_{3}$ observed experimentally for the $\left[\mathrm{M}+\mathrm{H}^{+}\right.$ions.

Additionally, more $\mathrm{H} / \mathrm{D}$ scrambling in the ions that lose $\mathrm{CH}_{3}$ might be expected because structure 7 can be attained more easily; this too is observed experimentally. Tables 3-6 present theoretical relative abundances for statistical scrambling and the experimentally observed abundances. Using Table 3 as an example, for statistical scrambling that involves ammonia loss, a ratio of 3.0:5.0 $(=0.60)$ for the abundances of the $m / z$ 77:78 ion should be observed. The experimentally observed ratio is $3.0: 5.0(=0.60)$. The ratio of the theoretical to experimental ratio is 1.0 , which indicates complete scrambling. For the loss of methane, the theoretical ratio should be 1.0:1.0 $(=1.0)$ for complete scrambling, but a ratio of 1.0:4.6 $(=0.22)$ is observed. Thus, the ratio of theoretical to experimental is 4.6, which indicates less than complete scrambling. The ratio for dissociations that involve $\mathrm{CH}_{4}$ or $\mathrm{CH}_{3}$ loss show that the latter occurs with more scrambling. For $N-d_{1}-2,5$-dimethylpyrrole the theoretical to experimental ratio is 4.6 for the $[\mathrm{M}-\mathrm{H}]^{+}$ion, whereas it is 1.3 for the $[\mathrm{M}+\mathrm{H}]^{+}$ion. In the case of 3,4-d ${ }_{2}-2,5$-dimethylpyrrole, the ratio for $[\mathrm{M}-\mathrm{H}]^{+}$is 4.3 and for $[\mathrm{M}+$ $\mathrm{H}]^{+}$the ratio is 3.3 .

\section{Conclusions}

The results obtained in this study indicate that the dissociation of $[\mathrm{M}+\mathrm{H}]^{+}$and $\left[\mathrm{M}-\mathrm{H}^{+}\right.$ions formed from dimethylpyrroles initially involves a ring expansion to a six-membered heterocycle. For the $[\mathrm{M}-\mathrm{H}]^{+}$ ion a protonated picoline is the most likely ion formed. The six-membered heterocyclic ring ion can dissociate subsequently by loss of $\mathrm{CH}_{4}$ (from $\left[\mathrm{M}-\mathrm{H}^{+}\right.$) or $\mathrm{CH}_{3}$ (from $[\mathrm{M}+\mathrm{H}]^{+}$). Competitive with this dissociation is another ring expansion to a seven-membered heterocycle. This seven-membered heterocyclic ring can then ring contract to protonated aniline or dihydroaniline, from which $\mathrm{NH}_{3}$ is lost.

The isomerization from the six- to seven-membered hetercyclic ion requires greater energy for the $[M-$ $\mathrm{H}]^{+}$ion than for the $[\mathrm{M}+\mathrm{H}]^{+}$ion, which is reflected in the decreased amount of $\mathrm{NH}_{3}$ loss observed for the
[M $-\mathrm{H}]^{+}$ion relative to the $\mathrm{CH}_{4}$ loss. This greater energy requirement is even further reflected in the $\mathrm{H} / \mathrm{D}$ scrambling. On the millisecond time scale of the quadrupole ion trap experiments, the seven-membered hetercyclic ion and/or the anilinium type ion can undergo extensive hydrogen scrambling. The ions formed via loss of $\mathrm{NH}_{3}$ show almost complete scrambling, regardless of the parent. Conversely, the $[\mathrm{M}+\mathrm{H}]^{+}$ion shows much more scrambling for $\mathrm{CH}_{3}$ loss than the $[\mathrm{M}-\mathrm{H}]^{+}$ion shows for $\mathrm{CH}_{4}$ loss, although this is still much less than the scrambling observed for the $\mathrm{NH}_{3}$ loss.

\section{References}

1. Parr, A. C.; Jason, A. J. Int. J. Mass Spectrom. Ion Phys. 1979, 30, 319-330.

2. Morgan, R. P.; Derrick, P. J. Org. Mass Spectrom. 1975, 10 , 563-578.

3. Borchers, F.; Levsen, K.; Schwarz, H.; Wesdemiotis, C.; Winkler, H. U. I. Am. Chem. Soc. 1977, 99, 6359-6365.

4. Busch, K. L.; Glish, G. L.; McLuckey, S. A. Mass Spectrometry/Mass Spectrometry: Techniques and Applications of Tandem Mass Spectrometry; VCH Publishers: New York, 1988.

5. Hart, K. J.; McLuckey, S. A.; Glish, G. L. I. Am. Soc. Mass Spectrom. 1992, 3, 680-682.

6. Bakhtiar, R.; Holznagel, C. M.; Jacobson, D. B. Organometallics 1993, 12, 621-623.

7. Kenttamaa, H. I. Org. Mass Spectrom. 1994, 29, 1-10.

8. Gross, M. L.; McLafferty, F. W. I. Am. Chem. Soc. 1971, 93, 1267-1268.

9. Gross, M. L.; Lin, P. H.; Franklin, S. J. Anal. Chem. 1972, 974-978.

10. Speranza, M.; Sefcik, M. D.; Henis, J. M. S.; Gaspar, P. P. J. Am. Chem. Soc. 1977, 99, 5583-5589.

11. Lifshitz, C.; Gibson, D. Int. J. Mass Spectrom. Ion Phys. 1980, 35, 365-370.

12. Ausloos, P.; Lias, S. G.; Buckley, T. J.; Rogers, E. E. Int. J. Mass Spectrom. Ion Phys. 1989, 92, 65-77.

13. Ausloos, P.; Jackson, J. A. A.; Lias, S. G. Int. J. Mass Spectrom. Ion Phys. 1980, 33, 269-283.

14. Heath, T. G.; Allison, J.; Watson, J. T. J. Am. Soc. Mass Spectrom. 1991, 2, 270-277.

15. Jackson, J. A.; Lias, S. G.; Ausloos, P. J. Am. Chem. Soc. 1977, 99, 7515-7521.

16. Dunbar, R. C. J. Am. Chem. Soc. 1975, 97, 1382-1384.

17. Leung, H-W.; Ichikawa, H.; Li, Y-H.; Harrison, A. G. J. Am. Chem. Soc. 1978, 100, 2479-2484.

18. Kuck, D. Mass Spectrom. Rev. 1990, 9, 287-233.

19. Kascheres, C.; Cooks, R. G. Anal. Chim. Acta 1988, 215, 223-232. 
20. Louris, J. N.; Cooks, R. G.; Skya, J. E. P.; Kelley, P. E.; Stafford, G. C. Jr.; Todd, J. F. J. Anal. Chem. 1987, 59, $1677-1685$.

21. Cooks, R. G.; Glish, G. L.; McLuckey, S. A.; Kaiser, R. E. Chem. Eng. 1991, 69, 26-413.

22. Louris, J. N.; Brodbelt, J. S.; Cooks, R. G.; Glish, G. L.; Van Berkel, G. J.; McLuckey, S. A. Int. J. Mass Spectrom. Ion Processes 1990, 96, 117-137.

23. Brodbelt, J. S.; Cooks, R. G. Int. J. Mass Spectrom. Ion Processes 1988, 86, 253-272.

24. Glish, G. L.; McLuckey, S. A.; Asano, K. G. J. Am. Soc. Mass Spectrom. 1990, 1, 166-173.

25. Lifshitz, C. Acc. Chem. Res. 1994, 27, 138-144.

26. Murthy, S.; Nagano, Y;; Beauchamp, J. L. J. Am. Chem. Soc. 1992, 114, 3573-3574.

27. Miller, F. A. J. Am. Chem. Soc. 1942, 64, 1543-1544.

28. Fulford, J. E.; March, R. E. Int. J. Mass Spectrom. Ion Phys. 1978, 26, 155-162.
29. Stafford, G. C., Jr.; Kelley, P. E.; Syka, J. E. P.; Reynolds, W. E.; Todd, J. F. J. Int. J. Mass Spectrom. Ion Processes 1984, 60, 85-98.

30. Cooks, R. G.; Beynon, J. H.; Caprioli, R. M.; Lester, G. R. Metastable lons; Elsevier Scientific: New York, 1973.

31. Haney, M. A.; Franklin, J. L. J. Chem. Phys. 1968, 48, 4093-4097.

32. Ranasinghe, Y.; Glish, G. L. J. Am. Soc. Mass Spectrom. 1996, $7,473-481$

33. Hart, K. J.; McLuckey, S. A.; Glish, G. L. Proceedings of the 40th Conference on Mass Spectrometry and Allied Topics; Washington, DC, June 1992.

34. Stewart, J. P. QCPE 455, Frank J. Seiler Research Laboratory, United States Air Force Academy, Colorado Springs, CO.

35. McLuckey, S. A.; Glish, G. L.; Van Berkel, G. J. Int. I. Mass Spectrom. Ion Processes 1991, 106, 213-235.

36. Loudon, G. M. Organic Chemistry; Benjamin/Cummings: Menlo Park, CA, 1988. 